\title{
Announcement
}

Neuro

Neuroepidemiology 2000;19:338-344

\section{Neuroméditerranée III:}

Neuroepidemiology in the Mediterranean Area

Palermo, Italy, April 8-10, 2001

This international conference will cover all major neurological pathologies. The local organizer is Prof. Giovanni Savettieri and the Organizing Secretariat is:

Serono Symposia

Via Casilina, 125

I-00176 Rome (Italy)

Tel. +3906 70384 513/506

Fax +390670384677

E-Mail roberta.cenci@serono.com

\section{KARGER}

(c) 2000 S. Karger AG, Basel

Fax +41613061234

E-Mail karger@karger.ch

www. karger.com

Accessible online at

www.karger.com/journals/ned 